\title{
A Qualitative Study of Online-Learning and a Crisis-Intervention Plan for Training in the COVID-19 situation
}

\author{
Dr. Siva Mahendran
}

Associate Literacy Trainer, Training Vision Institute and Adult Educator Professional, Institute of Adult Learning, Singapore

\begin{abstract}
Online learning and training are probably here to stay in the current Covid 19 situation and in the foreseeable future and we have to be at least prepared with a crisis intervention plan to be viable and sustain our normal way of learning and training, moving forward. We are able to use a variety of approaches to address these present and serious needs to keep on learning and training as best as we can. Thus we have to overcome our fear of the online mode of learning and training we have not being used to all along till the pandemic struck beginning of 2020 and a crisis intervention plan to manage the fear should be in order too to give us the confidence to carry on with our lives in a new normal the world over. This presentation is one such attempt to do just that.
\end{abstract}

Keywords-COVID-19, online-Learning, online training.

\section{INTRODUCTION}

COVID-19 has made a great impact in the way trainers train learners. It has created a situation where learning takes place at home online and in privacy, away from the prying eyes of colleagues at the workplace. The situation warrants for absolute concentration in making the best of the circumstances in the crisis situation we are presently facing.

We can make the most out of online training via the much talked about flipped-learning mode; getting learners to do more work themselves in preparing for lessons ahead and doing some practices themselves like checking out their texts, surfing the internet for learning resources etc. prior to the start of lessons online. Learning to use Zoom ${ }^{1}$ or other online-learning platforms itself is a learning experience for learners who have never been used to such approaches. After an initial period of familiarising learners with the online applications, the do's and don'ts, protocols to adhere and the various features of the applications, learners would be more confident to start learning hence.

\section{Online -Learning Mode - a boon or a bane}

Now Zoom, among other online modes of communication has become almost a buzz-word in most educational institutions and care must be taken to ensure a smooth and safe learning medium for all learners and trainers, moving forward.

Aside from technical and hardware considerations, online mode of training offers a novel way of introducing new concepts in the assimilation of knowledge via a differentiated, as opposed to the traditional face to face approach, to share information and knowledge. The use of online applications like Nearpod ${ }^{2}, \mathrm{Padlet}^{3}$, Canvas ${ }^{4}$, etc have made learning more experiential and even fun for all after the initial jitters in manoeuvring through all the rigmaroles and pitfalls that technology unwittingly offers.

The diagram below shows the processes that happen before, during and after the online mode of learning; quite self-explanatory for the prudent and discerning trainer. 


\section{Diagram 1}

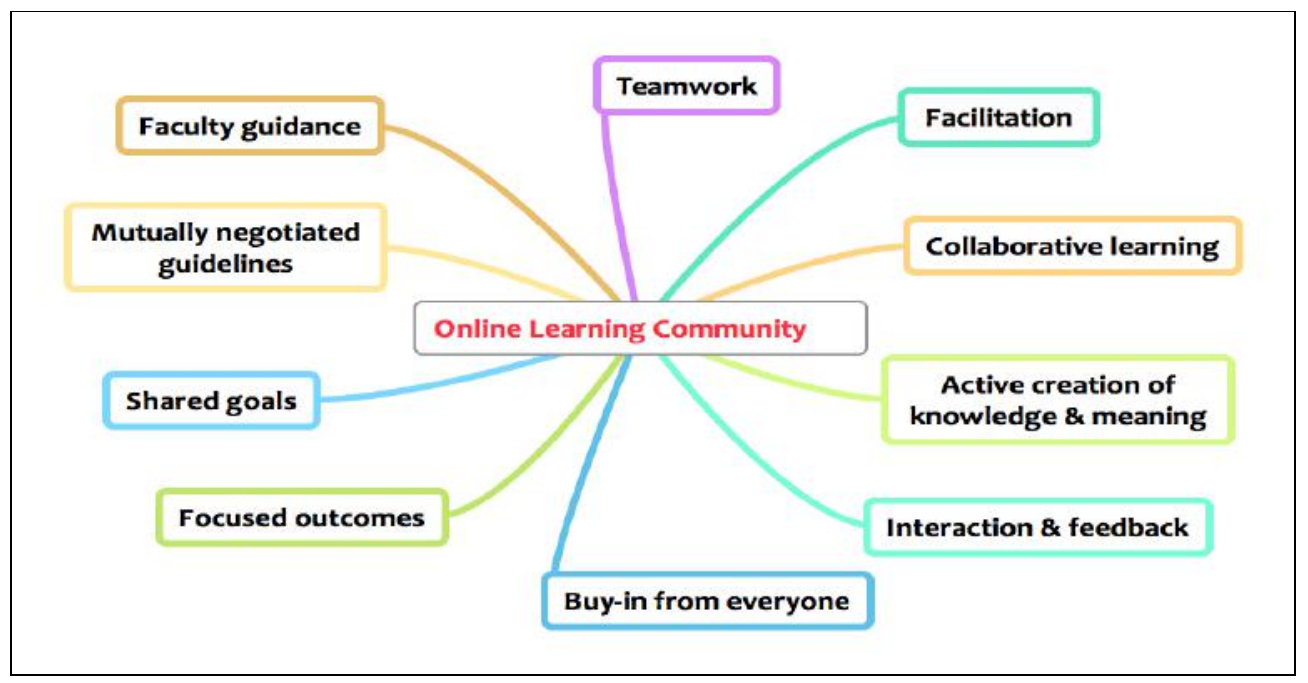

Source: https://www.bing.com/images

Compared to the traditional classroom learning, online learning does involve more preparation by the trainer to manage the training prior to and during the training sessions. Besides taking into considerations the entry requirements and the protocols to follow to allow learners to enter and exit the lesson, there are other considerations like internet speed, pacing of the lesson, the versatility of the learners to not only get used to the new learning mode but also keeping up with the rest of the class during the lesson as passive onlookers most of the time if they choose not to get much involved or are not familiar with the use of the application features like the whiteboard, breakout rooms, toggling the annotation links etc, which may overwhelm some of them, but over time they would probably get used to these and learning can become more of a flow than a hurdle to cross over at every turn of the lesson.

Some commonly used terms make online learning and training a cinch or a pain in the neck for the listener hearing them over and over again, as can be seen in the tongue-in-cheek Bingo-style diagram featured below:

\section{Diagram 2}

\begin{tabular}{|c|c|c|c|c|}
\hline $\begin{array}{l}\text { "HI, WHO } \\
\text { JUST } \\
\text { JOINED?" }\end{array}$ & $\begin{array}{l}\text { "CAN YOU } \\
\text { EMAIL THAT } \\
\text { TO EVERYONE? }\end{array}$ & "IS ${ }_{\text {HERE? }}$ ON & $\begin{array}{l}\text { "UH } \\
\text { YOURMIC } \\
\text { IS STIU ON." }\end{array}$ & $\begin{array}{l}\text { "YES, MY } \\
\text { VIDEO IS ON." }\end{array}$ \\
\hline $\begin{array}{l}\text { (SOMEONE } \\
\text { EATING } \\
\text { ON SCREEN) }\end{array}$ & $\begin{array}{l}\text { (LOUD PAINFUL } \\
\text { FEEDBACK) }\end{array}$ & $\begin{array}{l}\text { (CHILD OR } \\
\text { ANIMAL ON } \\
\text { SCREEN) }\end{array}$ & $\begin{array}{l}\text { "HI, CAN YOU } \\
\text { HEAR ME? }\end{array}$ & $\begin{array}{l}\text { "NO, ITS STIU } \\
\text { LOADING:" }\end{array}$ \\
\hline $\begin{array}{l}\text { (WAVES AT } \\
\text { NEW PERSON } \\
\text { ARRIVING) }\end{array}$ & $\begin{array}{c}\text { "CAN } \\
\text { EVERYONE } \\
\text { GO ON MUTE? }\end{array}$ & $\begin{array}{l}\text { "WERE IN } \\
\text { THIS } \\
\text { TOGETHER." }\end{array}$ & $\begin{array}{l}\text { "TM SORRY, } \\
\text { YOU CUT OUTT } \\
\text { THERE." }\end{array}$ & $\begin{array}{c}\text { (A } \\
\text { CEIUNG FAN } \\
\text { ON IN THE } \\
\text { BACKGROUND) }\end{array}$ \\
\hline $\begin{array}{c}\text { "SO (cuts out) } \\
\text { I CAN } \\
\text { (unintelligible) } \\
\text { BY (cuts out) } \\
\text { OK? }\end{array}$ & $\begin{array}{l}\text { "SORRY IM } \\
\text { LATE (INSERT } \\
\text { LAME EXCUSE.)" }\end{array}$ & $\begin{array}{l}\text { (SOMEONE } \\
\text { ZOOMING } \\
\text { FROM THE } \\
\text { BEDROOM) }\end{array}$ & $\begin{array}{l}\text { (SIDEBAR } \\
\text { CONVO } \\
\text { GOING ON } \\
\text { IN CHAT) }\end{array}$ & $\begin{array}{l}\text { TM SORRY: } \\
\text { I WAS ON } \\
\text { MUTE" }\end{array}$ \\
\hline $\begin{array}{l}\text { "IU HAVE TO } \\
\text { GET BACK } \\
\text { TO YOU." }\end{array}$ & $\begin{array}{l}\text { "CAN } \\
\text { EVERYONE } \\
\text { SEE ME?" }\end{array}$ & $\begin{array}{l}\text { "SORRY, I WAS } \\
\text { HAVING } \\
\text { CONNECTION } \\
\text { ISSUES." }\end{array}$ & $\begin{array}{l}\text { (SOMEONE } \\
\text { DRINKING } \\
\text { COFFEE } \\
\text { ON SCREEN) }\end{array}$ & $\begin{array}{l}\text { "SORRY, } 1 \\
\text { DIDNT CATCH } \\
\text { THAT. CAN } \\
\text { YOU REPEAT? }\end{array}$ \\
\hline
\end{tabular}

Source: https://www.bing.com/images 
The crux of the matteris to tolerate all the nuances and innuendoes associated with online learning or training so that one is not overwhelmed in the learning process over time.

Online Learning Survey of adult learners and newbies using Zoom

Afreestyle and general online survey of a group of 40 adult learners, both sexes, predominantly Chinese participants, between the age groups of 30 and 75 ,comprising 10 who Diagram 3 - Question 1 had just completed four lessons on Zoom and 30 newbies (all at approximately $\mathrm{CEFR}^{5} \mathrm{~A} 1$ to B1language levels) was done in the present Covid-19 situation. They had to answer just 5 questions via Survey Monkey. $\operatorname{com}^{6}$ and it was possible to get reasonably unanimous responseson their views about online learning using the Zoom application. The following are the results:

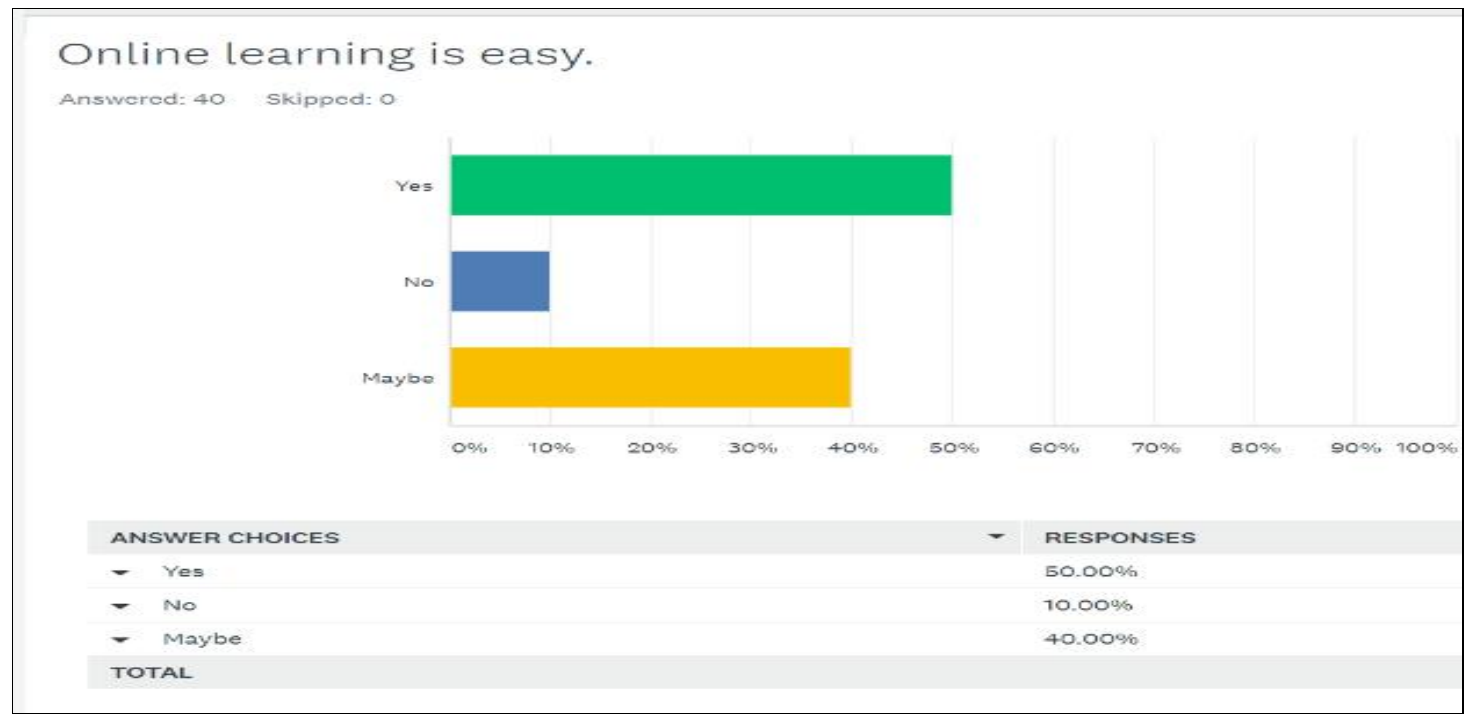

Diagram 4 - Question 2

I know how to do Zoom or online meetings.

Answered: 40 Skipped: 0

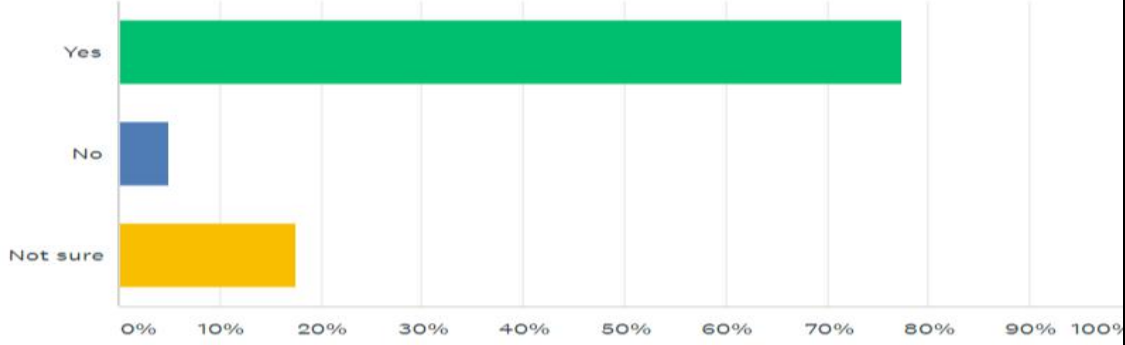

No 
International Journal of English Literature and Social Sciences, 5(4)

Jul-Aug 2020 /Available online: https://ijels.com/

\section{Diagram 5 - Question 3}

I can correct problems in Zoom or online meetings.

Answered: 40 skipped: 0

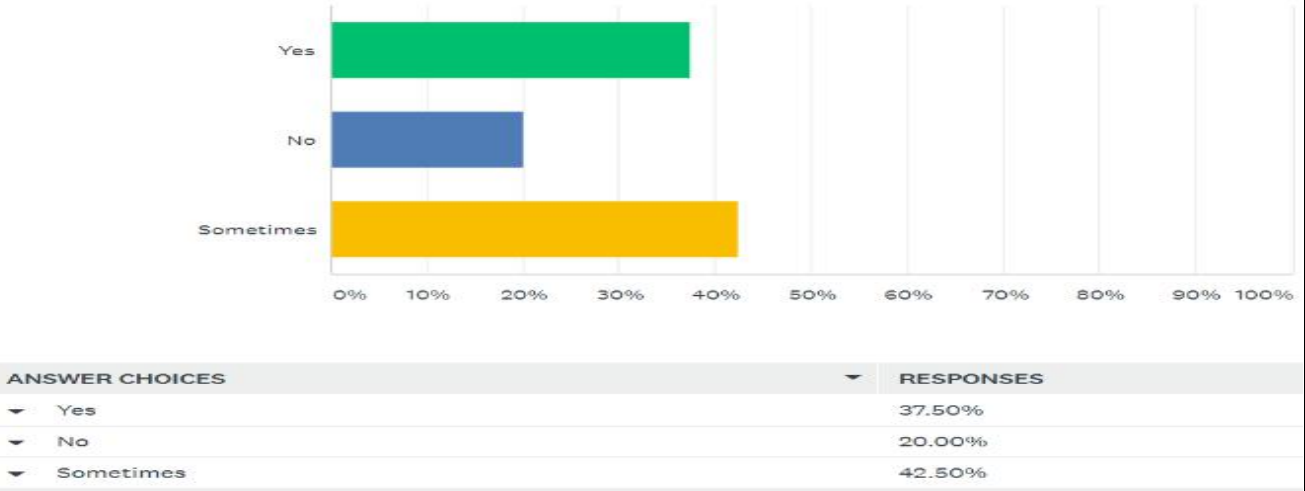

\section{Diagram 6 - Question 4}

Online lessons make learning more difficult.

Answered: 40 skipped: 0

ANSWER CHOICES

- Yes

- No

- Sometimes

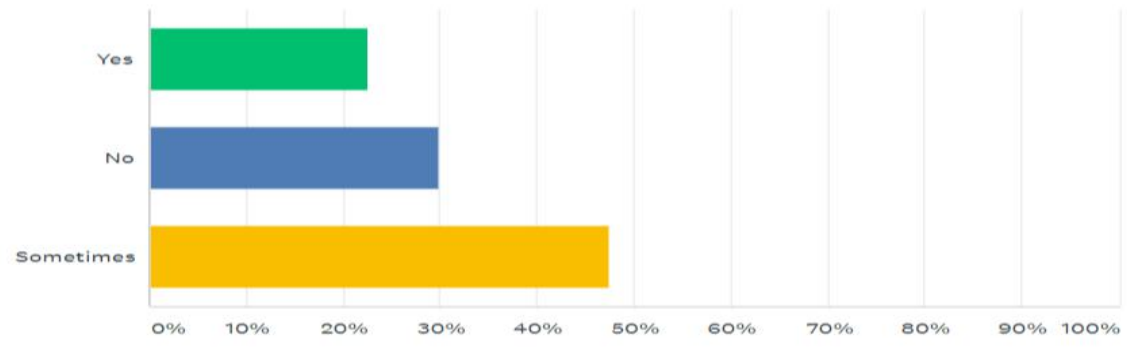

\section{Diagram 7 - Question 5}

I learn better in the classroom than online in Zoom.

Answered: 40 skipped: 0

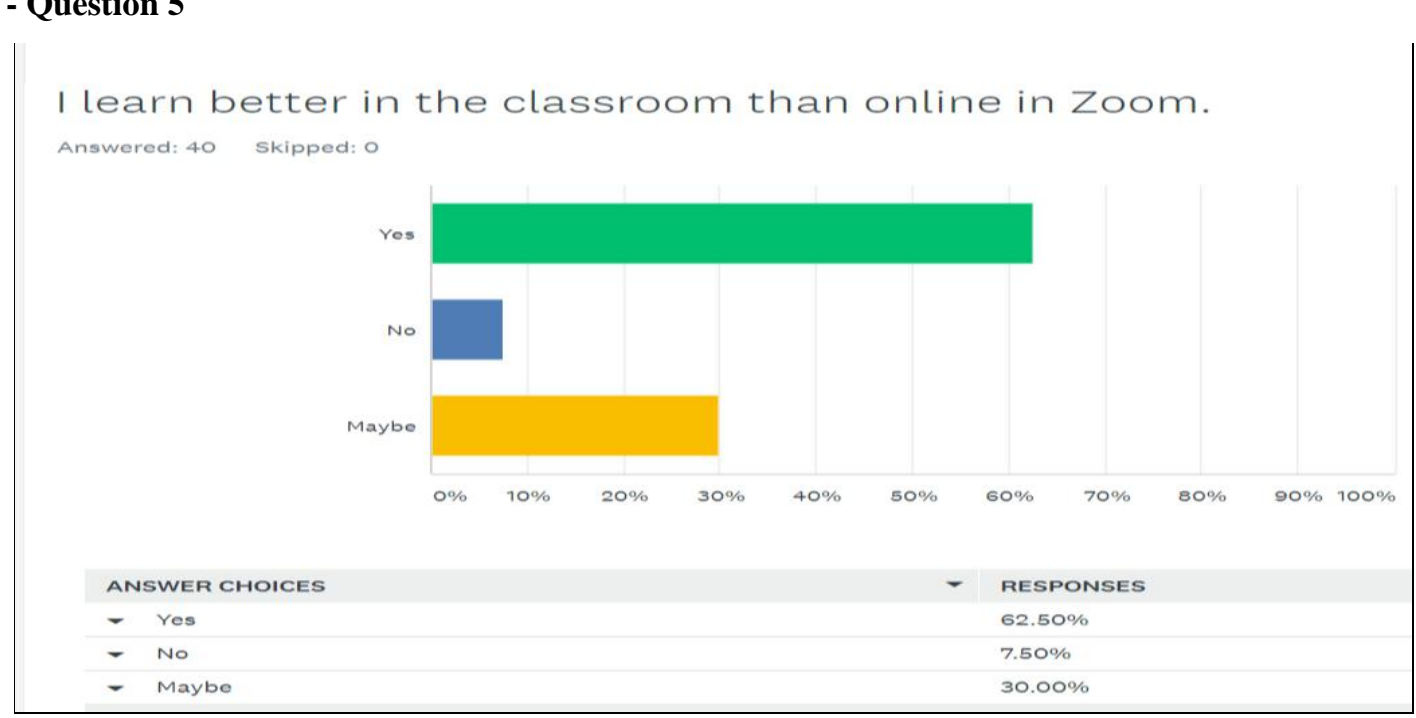

ANSWER CHOICES

- Yes

- No

Maybo

\section{RESPONSES}

$22.50 \%$

$30.00 \%$

$47.50 \%$ 


\section{Explanation of the survey results:}

Half of the respondents were generally comfortable with using Zoom to learn online and over three quarters of them were confident enough to be involved in a Zoom or online meeting. However just under $40 \%$ of the respondents are confident in being able to make corrections to any problems they may encounter in online meetings or learning mostly depending on the host to do those for them. Only $30 \%$ of them felt that online lessons are not difficult; which shows there is still a lot of work to do to get learners to be confident in the online learning mode as shown by the less than $10 \%$ of the respondents feeling learning online with Zoom is not a problem, in principle.

\section{Crisis - Intervention: Fear Factor and Remedial actions}

Most respondents I spoke to and observed during the Zoom lessons feared being locked out of the lesson for some reason or other, not confident to toggle between the different Zoom features like whiteboard, annotations to use, in-built or external microphone, video not working, etc; among others. Some respondents were also apprehensive on being recorded during the lesson on video so they try to hide the video or not show their faces until the photo-taking session happens at the start and end of the lesson for attendance-taking.

According to the Kubler-Ross Change Curve (Appendix 1), learners go through a process of denial to integration over time as they have to adjust to a different mindset to change their usual mode of face to face classroom learning to the online mode. They progress through denial to frustration, even depression in some cases before taking a chance to experiment, with a fear of failure looming all the time, progressing one step at a time to make decisions and finally acceptance in the form of integration of all the bits and pieces of the learning puzzle in the online mode. Throughout the stages of online learning, the trainer has to hand-hold them all the way in bite-sized and piece-meal stages of the lessons to get learners to confidently cruise through, from the shallow end of the river of knowledge (downloading the application, affixing the password and identification number to gain access into the learning portal like Zoom) to the deeper parts where they may swim against the tide of errors and difficulties in navigating through unfamiliar terms and procedures (whiteboard, breakout rooms, annotations, chat icon, drawings, etc.). The trainer has to be patient and use the initial and earlier parts of a lesson to run through the ground-rules and procedures before embarking on the more serious learning journey. Here breakout rooms are useful to get learners to practice in smaller groups and do their discussions and write-upson Padlet or large writing on paper for presentations later in the lesson.The trainer could also move into the breakout groups, one at a time, to discuss salient points of the lesson and get the feedback from the learners.

Remedial actions could also be taken to inform learners to be prepared earlier to attend the lessons by at least 15 minutes from the start so the trainer has to get ready at least 30 minutes earlier too so that any kinks or problems could be addressed before the lesson starts. Group chats on the various social media applications could also be done prior to the lessons to guide the learners and get their feedback on past lessons or the lesson ahead so during the lesson, there would be little or no problems encountered by all for a smooth learning journey through the lesson.

It would be prudent to always keep the contact telephone numbers of the training company's office staff at hand in case of any problems that may crop up at any point prior to, in or after the online lesson.

Trainers and learners could also attend online meetings or workshops as they come to know the various online learning markets and programs in use and be more adept over time to handle future online learning needs.

Using the SMART techniques (Appendix 2) will certainly help learners to be less confused, more confident and motivated in learning online too.

\section{Offline or Online, software or hardware}

Offline and online modes of a lesson do make a difference as in the former, there is no worry about the internet connection and any mistakes made or trials done do not impact the lesson at all. Online, learners and the trainer have to strictly follow the lesson-protocols and guidelines always and make sure there are no hiccups along the way.

Online lessons do entail proper use of time management and bite-sized lessons (preferably less than an hour at a time) to ensure the learners do not get tired or eye-sore watching the screen all the time. It would be prudent to give them a short break from time to time for toilet breaks, do back stretches, rest or to have a drink or some food so that they would be/stay more involved after the intermission. Different learners have different expectations during a lesson and the trainer has to know each and everyone's learning attitude and attributes to do differentiated training to match the learners' expectations throughout the online learning mode for best results.

While the software is all there in the internet to download and use, legally authorised of course, the hardware monitor, video-camera, the internal processing unit and enough storage space, fully-charged battery microphone 
and speaker system, etc. needs to be in place too to get the computer or mobile phones to work well during the onlinelessons or trouble shooting problems may arise at any point in time and spoil the learners' motivation to learn with the resultant waste of precious time too.

\section{CONCLUSION}

Whether we like it or not, online learning and training is here to stay, during and post- Covid -19 circuit breaker or lockdown period and as trainers, we have to keep learning about online modes of learning and the use of different applications like Padlet, MindMeister ${ }^{7}$ (a mind-mapping tool), English $\mathrm{Central}^{8}$, Nearpod ${ }^{9}$, etc, to stay current and ready for more innovative learning and training approaches in time to cater to our learners' learning needs evermore.

\section{REFERENCES}

[1] https://zoom.us/

[2] https://nearpod.com/library/

[3] https://padlet.com/

[4] https://www.instructure.com/canvas/en-au

[5] https://www.coe.int/en/web/common-europeanframework-reference-languages/level-descriptions

[6] https://www.surveymonkey.com/

[7] https://www.mindmeister.com/

[8] https://www.englishcentral.com/

[9] https://nearpod.com/

\section{Appendices}

1.

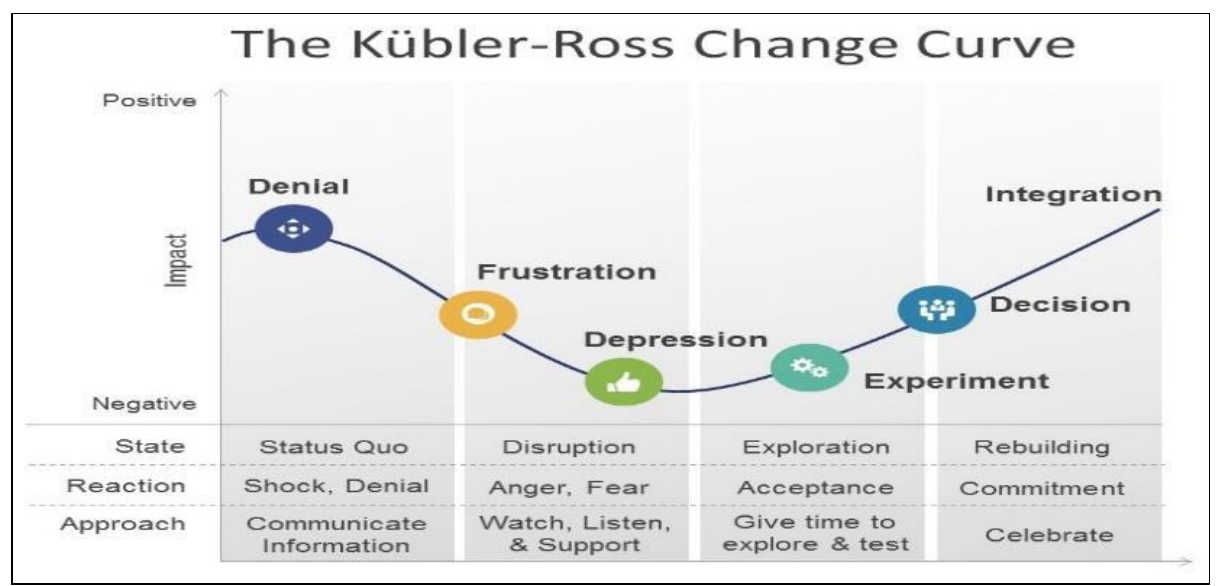

Source: https://images.search.yahoo.com/search/images

2.

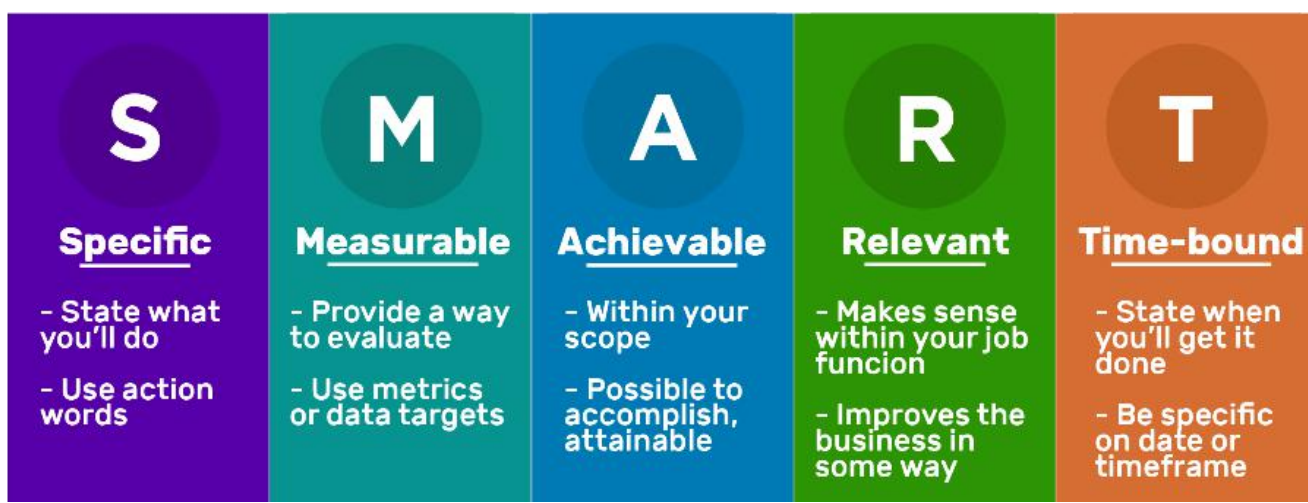

Source: https://images.search.yahoo.com/search/images 